\title{
The reduction process of petroleum content in marine oil spill in Jiaozhou Bay
}

\author{
Dongfang Yang ${ }^{1,2, *}$, Haixia $\mathrm{Li}^{1}$, Dong Lin ${ }^{1}$, Yuan Zhang ${ }^{1}$, Qi Wang ${ }^{1}$ \\ ${ }^{1}$ Accountancy School, Xijing University, Xi'an 710123, China; \\ ${ }^{2}$ North China Sea Environmental Monitoring Center, SOA, Qingdao 266033, China;
}

\begin{abstract}
According to the survey data about the waters of Jiaozhou Bay in May, September, and October 1993, this paper studies the content of PHC and its horizontal distribution in the surface waters of Jiaozhou Bay. The result shows that the range of PHC content in the waters of Jiaozhou bay is $4.16-51.00 \mu \mathrm{g} / \mathrm{L}$, which conforms to the national first, second and third water quality standards. In terms of PHC content, the water quality of Jiaozhou Bay is slightly polluted by PHC content in May, September and October. In May, the range of PHC content in the water of Jiaozhou Bay is $4.16-51.00 \mu \mathrm{g} / \mathrm{L}$, which is slightly polluted by PHC content. In the center of east waters, the water quality is slightly polluted by PHC content and the range of PHC content in other water fields of Jiaozhou Bay is $4.16-48.40 \mu \mathrm{g} / \mathrm{L}$ which indicates that the water quality is not polluted by PHC content. In September, the range of PHC content in the waters of Jiaozhou Bay is $6.17-12.70 \mu \mathrm{g} / \mathrm{L}$, which is not polluted by PHC content. In October, the range of PHC content is $11.40-11.80 \mu \mathrm{g} / \mathrm{L}$, indicating that the waters of Jiaozhou Bay are not polluted by PHC. The content of PHC in the waters of Jiaozhou Bay only has one source, the transportation of marine oil spill, and the PHC content transported is $12.70-51.00 \mu \mathrm{g} / \mathrm{L}$. Therefore, as time changes, the ocean polluted by PHC content resulting from marine oil spill has gradually reduced over the course of the year. The marine oil spill has caused the waters in May to be slightly polluted by the PHC content. By September, the waters are not polluted by the PHC content. And then, in October, the marine oil spill has disappeared.
\end{abstract}

\section{Introduction}

On the eastern coast of Jiaozhou Bay, a terminal oil storage base has been established. As a result, there have been many oil tankers going to and from Jiaozhou Bay, resulting in the occurrence of marine oil spills. Then the marine oil spill transports the PHC content to the bay waters [1-11]. Based on the survey data in 1993, this paper analyzes the content, horizontal distribution and source of PHC in Jiaozhou Bay waters, studies the water quality, source and quantity of PHC in Jiaozhou Bay waters, and determines the PHC content in the waters of Jiaozhou Bay and the pollution degree, which provide a scientific theoretical basis for protecting the marine environment and maintaining sustainable ecological development.

\section{Survey waters, materials and methods}

2.1 The natural environment of Jiaozhou Bay. Jiaozhou Bay is located in the southern part of Shandong Peninsula. Its geographical position is between $120^{\circ} 04^{\prime}-120^{\circ} 23^{\prime} \mathrm{E}$ and $35^{\circ} 58^{\prime}-36^{\circ} 18^{\prime} \mathrm{N}$. It is bounded by the line connecting Tuan Island and Xuejia Island, and is connected to the Yellow Sea. With about $446 \mathrm{~km}^{2}$ in the area and about $7 \mathrm{~m}$ in the average water depth, it is a typical semi-enclosed bay. There are more than a dozen rivers entering the sea in Jiaozhou Bay, among which the Dagu River, Yang River and the Haibo River, Licun River and Loushan River in Qingdao City with larger runoff and sand content $[12,13]$.

2.2 Materials and methods. The survey data of PHC content in Jiaozhou Bay in May, September and October 1992 used in this study are provided by the North Sea Monitoring Center of the State Oceanic Administration. Seven stations were set up in the waters of Jiaozhou Bay to take water samples: stations H3101, H3102, H3103, H3104, H3105, H3106 and H3107 (Figure 1). They got water samples three times in May, September and October 1993, respectively.Got were water samples by the water depth (two water samples from the surface and bottom layers when the depth $>10 \mathrm{~m}$, and only ones from the surface layer when the depth $<10 \mathrm{~m}$ ) for investigation and sampling. The survey of PHC content in Jiaozhou Bay water body was conducted by the national standard method, recorded in the national "Marine Monitoring Code" (1991) [14].

\footnotetext{
* Corresponding author:*dfyang@gzmu.edu.cn
} 


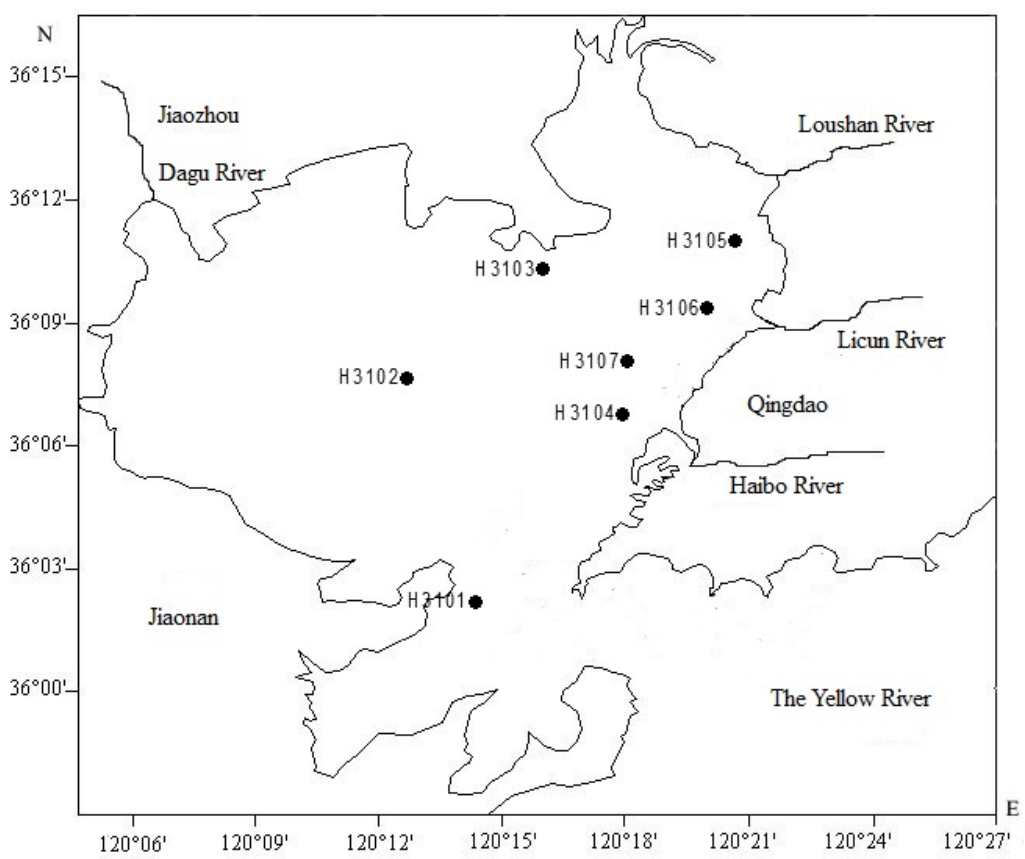

Fig.1 Investigation sites in Jiaozhou Bay

\section{Results}

3.1 PHC content. In terms of PHC content in the ocean, the nation has put forward the national water quality standards for Class I and Class II seawater $(50 \mu \mathrm{g} / \mathrm{L})$, Class III $(300 \mu \mathrm{g} / \mathrm{L})$ and Class IV $(500 \mu \mathrm{g} / \mathrm{L})$.

In May, the PHC content in the waters of Jiaozhou Bay ranges from 4.16 to $51.00 \mu \mathrm{g} / \mathrm{L}$, which meets the water quality standards of Class I, II, and III. In September, the PHC content in the waters of Jiaozhou Bay ranges from 6.17 to $12.70 \mu \mathrm{g} / \mathrm{L}$, which meets the national water quality standards for Class I and II seawater. In October, the PHC content in the waters of Jiaozhou Bay ranges from 11.40 to $11.80 \mu \mathrm{g} / \mathrm{L}$, which meets the national water quality standards for Class I and II seawater. Therefore, in May, September and October, the content of PHC in the waters of Jiaozhou Bay ranges within $4.16-51.00 \mu \mathrm{g} / \mathrm{L}$, which meets the national water quality standards of Class I, II, and III. This shows that in terms of PHC content, the water quality of the entire Jiaozhou Bay is slightly polluted by PHC in May, September and October (Table 1).

Tab.1 The surface water quality in Jiaozhou bay in May, September and October

\begin{tabular}{|l|l|l|l|}
\hline & \multicolumn{1}{|c|}{ May } & \multicolumn{1}{|c|}{ September } & October \\
\hline PHC content in seawaters $/ \mu \mathrm{g} \cdot \mathrm{L}^{-1}$ & $4.16-51.00$ & $6.17-12.70$ & $11.40-11.80$ \\
National water quality standards & Class I, II, III & Class I, II & Class I, II \\
\hline
\end{tabular}

\subsection{Horizontal distribution in the surface later.} In May, in the eastern part of Jiaozhou Bay, the PHC content reaches a high level of $51.00 \mu \mathrm{g} / \mathrm{L}$ at $\mathrm{H} 3107$ station in the eastern central waters, forming a high content area of PHC with $\mathrm{H} 3107$ station as the center and a series of concentric circles with different gradients. The PHC content decreases from the high content of $51.00 \mu \mathrm{g} / \mathrm{L}$ in the center to the surroundings along the gradient, to $31.60 \mu \mathrm{g} / \mathrm{L}$ in the central waters of the bay, $27.00 \mu \mathrm{g} / \mathrm{L}$ in the northern waters of the bay, and $4.16 \mu \mathrm{g} / \mathrm{L}$ in the waters of the bay mouth (Figure 2). 


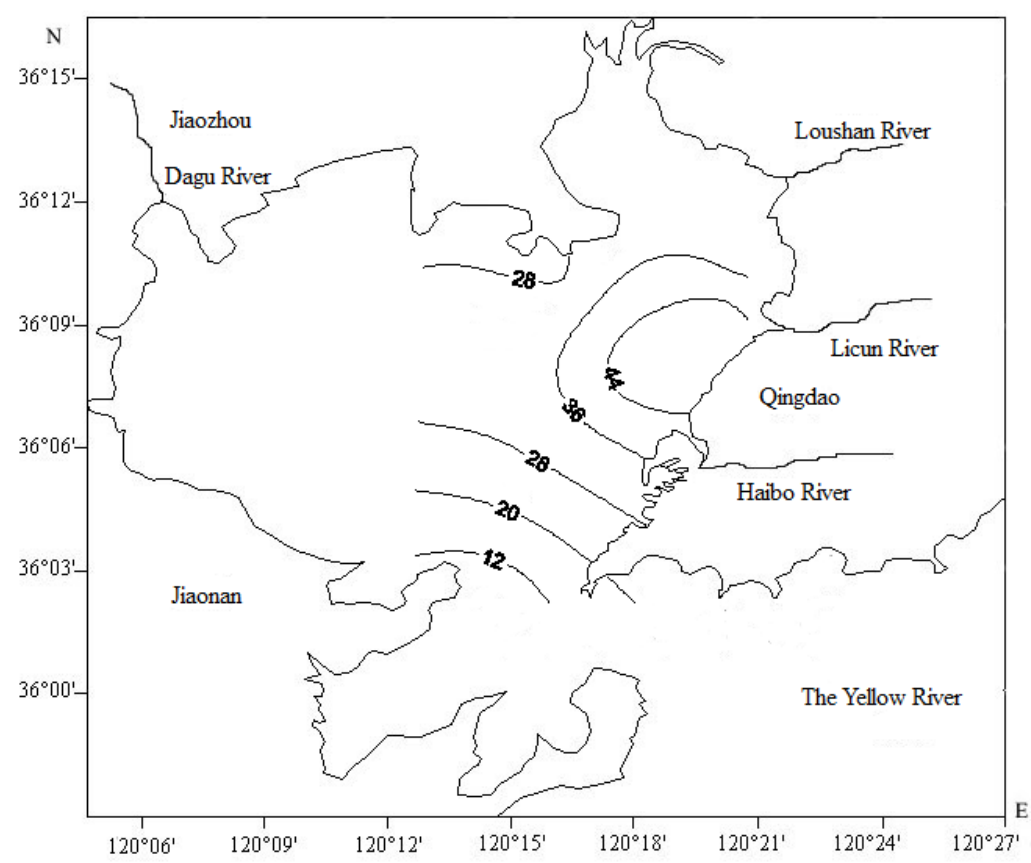

Fig.2 PHC content distribution in the surface waters of Jiaozhou Bay in May $(\mu \mathrm{g} / \mathrm{L})$

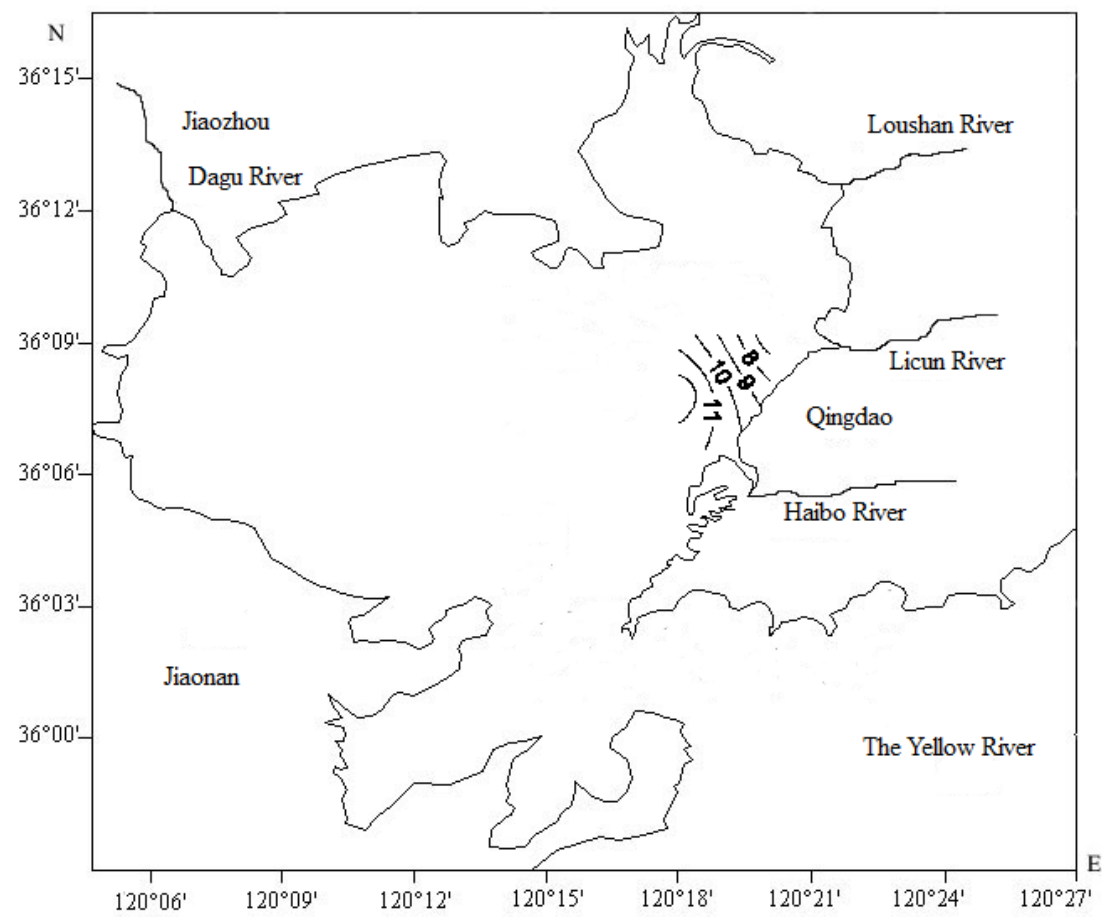

Fig.3 PHC content distribution in the surface waters of Jiaozhou Bay in September $(\mu \mathrm{g} / \mathrm{L})$

In September, in the eastern part of Jiaozhou Bay, the PHC content reaches a high level of $12.70 \mu \mathrm{g} / \mathrm{L}$ at $\mathrm{H} 3107$ station in the eastern central waters, forming a high content area of PHC with $\mathrm{H} 3107$ station as the center and a series of concentric circles with different gradients. The PHC content decreases from the high content of $12.70 \mu \mathrm{g} / \mathrm{L}$ in the center along the gradient to the surroundings, to $6.17 \mu \mathrm{g} / \mathrm{L}$ in the northeast waters of the bay, and $11.40 \mu \mathrm{g} / \mathrm{L}$ in the southeast waters of the bay (Figure 3).

In October, at $\mathrm{H} 3103$ station in the coastal waters of the northern Jiaozhou Bay, the content of PHC reaches a high level of $11.80 \mu \mathrm{g} / \mathrm{L}$, forming a high content area of PHC in the northern coastal waters. Taking the high content area of PHC as the center, it forms a series of parallel lines with different gradients. The content of PHC decreases from the high content of $11.80 \mu \mathrm{g} / \mathrm{L}$ in the center along the gradient to $11.40 \mu \mathrm{g} / \mathrm{L}$ in the southeast coastal waters. 


\section{Discussion}

4.1 Water quality. In May, September and October, the content of PHC in the waters of Jiaozhou Bay ranges from 4.16 to $51.00 \mu \mathrm{g} / \mathrm{L}$, which are in line with the national water quality standards for Class I and Class II $(50 \mu \mathrm{g} / \mathrm{L})$ and the water quality standards for Class III $(300 \mu \mathrm{g} / \mathrm{L})$. This shows that in terms of PHC content, in May, August and October, the water quality of Jiaozhou Bay is slightly polluted by PHC.

In May, the content of PHC in the waters of Jiaozhou Bay ranges within $4.16-51.00 \mu \mathrm{g} / \mathrm{L}$, and the waters of Jiaozhou Bay are slightly polluted by PHC. At station $\mathrm{H} 3107$ in the eastern central water area, the PHC content is $51.00 \mu \mathrm{g} / \mathrm{L}$, which indicates that the water quality of this water area meets the water quality standards of Class III in terms of PHC content, and the PHC content is greater than $0.050 \mu \mathrm{g} / \mathrm{L}$, so the water quality is slightly polluted by PHC. In Jiaozhou Bay, except for the central waters in the east, the PHC content varies from 4.16 to $48.40 \mu \mathrm{g} / \mathrm{L}$, which indicates that the water quality of this water area meets the water quality standards of Class I and II in terms of PHC content. The water quality has not been polluted by $\mathrm{PHC}$ and has clean water quality (Figure 2).

In September, the content of PHC in the waters of Jiaozhou Bay ranges within 6.17-12.70 $\mu \mathrm{g} / \mathrm{L}$, and the waters of Jiaozhou Bay are not polluted by PHC, which shows that the water quality of this water area, in terms of PHC content, meets the water quality standards of Class I and II, and the PHC content is far less than $50.00 \mu \mathrm{g} / \mathrm{L}$. Therefore, the water quality is not polluted by $\mathrm{PHC}$ and the water is clean (Figure 3 ).

In October, the content of PHC in the waters of Jiaozhou Bay ranges within $11.40-11.80 \mu \mathrm{g} / \mathrm{L}$, and the waters of Jiaozhou Bay are not polluted by PHC, which shows that the water quality of this water area, in terms of PHC content, meets the water quality standards of
Class I and II, and the water quality is not polluted by PHC. The water is clean. Moreover, the PHC content in the water body of Jiaozhou Bay is very uniform.

Therefore, in May, the water quality of the central waters in the east part is slightly polluted by PHC while in other waters of Jiaozhou Bay, the water quality is not polluted by PHC. In September and October, the water quality of Jiaozhou Bay is not polluted by PHC content.

4.2 Sources. In May, a high-content area of PHC is formed in the waters of eastern center of Jiaozhou Bay, which indicates that the source of PHC is the transportation of oil spilled at sea, and its PHC content is $51.00 \mu \mathrm{g} / \mathrm{L}$. The transported PHC content declines along the gradient, which leads to a decrease in the PHC content gradient to the surrounding area, reaching $31.60 \mu \mathrm{g} / \mathrm{L}$ in the central waters of the bay, $27.00 \mu \mathrm{g} / \mathrm{L}$ in the northern waters of the bay, and $4.16 \mu \mathrm{g} / \mathrm{L}$ in the waters of the bay mouth.

In September, a high-content area of PHC is formed in the waters of eastern center of Jiaozhou Bay, which indicates that the source of PHC is the transportation of oil spilled at sea, and its PHC content is $12.70 \mu \mathrm{g} / \mathrm{L}$. The transported PHC content decreases along the gradient, which causes the PHC content gradient to decrease to the surroundings, reaching $6.17 \mu \mathrm{g} / \mathrm{L}$ to the northeast waters of the bay and $11.40 \mu \mathrm{g} / \mathrm{L}$ to the southeast waters of the bay.

In October, the change in PHC content does not exceed $0.50 \mu \mathrm{g} / \mathrm{L}$ from the coastal waters in the northern part of Jiaozhou Bay to the coastal waters in the southeast, which shows that in the waters of Jiaozhou Bay, the PHC content is very uniform, and there is almost no source to transport PHC.

The PHC content in the waters of Jiaozhou Bay has only one source, which is mainly from the transportation of marine oil spill (Table 2). The PHC content from the oil spilled at sea is $12.70-51.00 \mu \mathrm{g} / \mathrm{L}$.

Tab.2 The PHC content in Jiaozhou Bay has the only source

\begin{tabular}{|c|c|}
\hline The only source & Transportation of marine oil spill \\
\hline PHC content $/ \mu \mathrm{g} \cdot \mathrm{L}^{-1}$ & $12.70-51.00$ \\
\hline
\end{tabular}

4.3 The change in the content of source. In May, September and October, the PHC content in the waters of Jiaozhou Bay has the only source, mainly from the transportation of oil spilled at sea.

In May, the source of PHC content is the transportation of oil spilled at sea, and its PHC content is $51.00 \mu \mathrm{g} / \mathrm{L}$.

In September, the source of PHC content is the transportation of oil spilled at sea, and its PHC content is $12.70 \mu \mathrm{g} / \mathrm{L}$.

In October, there is no source of PHC content.

In different months, there is only one source of PHC content, that is, the transportation of oil spilled at sea. Moreover, as time changes, the PHC content of the oil spilled at sea gradually decreases until it disappears.
4.4 The pollution degree of source. The PHC content in the waters of Jiaozhou Bay has only one source, mainly from the transportation of oil spilled at sea (Table 2).

In May, the PHC content of marine oil spilled to the waters of Jiaozhou Bay exceeds the national seawater quality standards of Class I and II, $50 \mu \mathrm{g} / \mathrm{L}$, and meets the national seawater quality standard of Class III, $300 \mu \mathrm{g} / \mathrm{L}$. This indicates that the marine oil spill slightly causes the pollution of PHC content.

In September, the PHC content of the marine oil spilled to the waters of Jiaozhou Bay meets the national seawater quality standards of Class I and II, $50 \mu \mathrm{g} / \mathrm{L}$, which indicates that the marine oil spill does not lead to the pollution of PHC content.

In October, the PHC content of the marine oil spilled to Jiaozhou Bay has disappeared, indicating that there is 
not contaminated by the PHC content caused by marine oil spill.

This shows that in a year, as time changes, the pollution of PHC content in the sea caused by marine oil spills have gradually reduced. From the slight pollution of PHC content caused by marine oil spill in May to the absence of PHC content pollution in September, and the disappearance of the marine oil spill in September, it shows that marine traffic has improved the awareness of marine environmental protection and minimized the PHC content pollution of marine waters.

\section{Conclusion}

In May, September and October, the content of PHC in the waters of Jiaozhou Bay ranges in 4.16-51.00 $\mu \mathrm{g} / \mathrm{L}$, which conforms to the national seawater quality standards of Class I, II and III. This shows that in terms of PHC content, the waters of Jiaozhou Bay are slightly polluted by PHC content in May, September and October.

In May, the content of PHC in the waters of Jiaozhou Bay ranges from 4.16 to $51.00 \mu \mathrm{g} / \mathrm{L}$, and the waters of Jiaozhou Bay are slightly polluted by the PHC content. In the eastern central waters, the water is slightly polluted by the PHC content of $51.00 \mu \mathrm{g} / \mathrm{L}$. Except for the eastern central waters, the PHC content in other waters of Jiaozhou Bay ranges from 4.16 to $48.40 \mu \mathrm{g} / \mathrm{L}$, and the water is not polluted by the PHC content. In September, the content of PHC in the waters of Jiaozhou Bay ranges from 6.17 to $12.70 \mu \mathrm{g} / \mathrm{L}$, and the waters of Jiaozhou Bay are not polluted by PHC content. In October, the content of PHC in the waters of Jiaozhou Bay ranges from 11.40 to $11.80 \mu \mathrm{g} / \mathrm{L}$, and the waters of Jiaozhou Bay are not polluted by the content of PHC as well.

The content of PHC in the waters of Jiaozhou Bay has the only source that is the transportation of marine oil spills. In addition, the content of PHC from oil spills at sea is $12.70 \sim 51.00 \mu \mathrm{g} / \mathrm{L}$. In different months, there is only one source of PHC content, that is, the transportation of oil spilled at sea. Moreover, as time changes, the PHC content of the oil spilled at sea gradually decreases until it disappears. Therefore, over the course of the year, with the change of time, the degree of PHC pollution caused by marine oil spills has gradually decreased. From the slight pollution of $\mathrm{PHC}$ content caused by marine oil spill in May to the absence of PHC content pollution in September, and the disappearance of the marine oil spill in September. In this way, with the improvement of environmental protection awareness, the pollution of PHC content in the marine waters is gradually decreasing.

\section{References}

1. Yang Dongfang, Zhang Jing, Lu Jibin, Gao Zhenhui, Chen Yu.Examination of Silicate Limitation of Primary Production in the Jiaozhou Bay, North ChinaI.Silicate Being a Limiting Factor of Phytoplankton Primary Production[J]. Chin. J. Oceanol. Limnol. 2002, 20( 3): 208-225
2. Yang Dongfang, Zhang Jing, Gao Zhenhui Chen Yu, Sun Pei-yan. Examination of Silicate Limitation of Primary Production in the Jiaozhou Bay, North China II. Critical Value and Time of Silicate Limitation and Satisfaction of the Phytoplankton Growth[J]. Chin. J. Oceanol. Limnol. 2003,21(1) : 46-63.

3. Yang Dongfang, Gao Zhenhui, Chen Yu, Zhang Jing, Wang Pei-gang. Examination of Silicate Limitation of Primary Production in the Jiaozhou Bay, North China III. Judgment Method, Rules and Uniqueness of Nutrient Limitation among N, P, and Si[J]. Chin. J. Oceanol. Limnol. 2003, 21(2):114-133.

4. Yang Dongfang, Gao Zhenhui, Zhang Jing, Cui Wenlin, Shi Qiang. Examination of Daytime Length's Influence on Phytoplankton Growth in Jiaozhou Bay, China[J]. Chin. J. Oceanol. Limnol. 2004, 22(1): 70-82.

5. Yang Dongfang, Gao Zhenhui, Chen Yu Wang Pei-gang, Sun Pei-yan. Examination of Seawater Temperature's Influence on Phytoplankton Growth in Jiaozhou Bay, North China[J]. Chin. J. Oceanol. Limnol. 2004, 22(2): 166-175.

6. Yang Dongfang, Chen Yu, Gao Zhenhui, Zhang Jing, Wang Fan. Silicon limitation on primary production and its destiny in Jiaozhou Bay, China IV Transect offshore the coast with estuaries[J]. Chin. J. Oceanol. Limnol. 2005, 23(1): 72-90.

7. Yang Dongfang, Gao Zhenhui, Wang Pei-gang, Sun Pei-yan Liu Shuang. Silicon limitation on primary production and its destiny in Jiaozhou Bay, ChinaV Silicon deficit process[J]. Chin. J. Oceanol. Limnol. 2005, 23(2): 169-175.

8. Yang Dongfang, Gao Zhenhui, Sun Peiyan, Zhao Sheng, Zhang Youchi. Silicon limitation on primary production and its destiny in Jiaozhou Bay, ChinaVI The ecological variation process of the phytoplankton [J]. Chin. J. Oceanol. Limnol. 2006, 24(2): 186-203.

9. Yang Dongfang, Gao Zhenhui, Yang Yingbin, Sun Peiyan, Wang Xingping. Silicon limitation on primary production and its destiny in Jiaozhou Bay, ChinaVII The Complementary mechanism of the earth ecosystem [J]. Chin. J. Oceanol. Limnol. 2006, 24(4): 401-412.

10. Yang Dongfang, Wu Jianping, Chen Shengtao and Lu Qing. The teleconnec tion between marine silicon supply and desertification in China[J]. Chin. J. Oceanol. Limnol. 2007, 25(1): 116-122.

11. YANG Dongfang, MIAO Zhenqing, SHI Qiang, CHEN Yu, CHEN Guoguang. Silicon limitation on primary production and its destiny in Jiaozhou Bay, China VIII: The variation of atmospheric carbon determined by both phytoplankton and human[J]. Chin. J. Oceanol. Limnol. 2010, 28(2): 416-425 .

12. YANG Dongfang, MIAO Zhenqing, CHEN Yu, SHI Qiang, XU Huanzhi. Human discharge and phytoplankton takeup for the atmospheric carbon balance [J]. Atmospheric and Climate Sciences, 2011, 
1(4): 189-196.

13. Yang Dongfang, Ding Ziru, Miao Zhenqing, Xu Huanzhi, Bai Hongyan. Input Quantity and Distribution of hexachlorocyclohexane $(\mathrm{HCH})$ in the Jiaozhou Bay Water[J]. Journal of Water Resource and Protection. 2012, 4(3): 140-148.

14. State Oceanic Administration. The Specification for Marine Monitoring $[Z]$. Beijing: China Ocean Press, 1991. 